\title{
Letra, huella, trazo: reflexión sobre la historia, la memoria y el olvido desde el sentipensar
}

\section{Artículo de reflexión}

\section{Jesús Holmes Muñoz Gómez}

Universidad Distrital Francisco José de Caldas,

Colombia

memoriaviaje@gmail.com

Recibido: 14 de agosto de 2018

Aprobado: 18 de octubre de 2018

Cómo citar este artículo: Muñoz Gómez, Jesús Holmes (2019). Letra, huella, trazo: reflexión sobre la historia, la memoria y el olvido desde el sentipensar. Calle 14: revista de investigación en el campo del arte 14(26). pp. 398-411. DOI: https://doi.org/10.14483/21450706.15012 


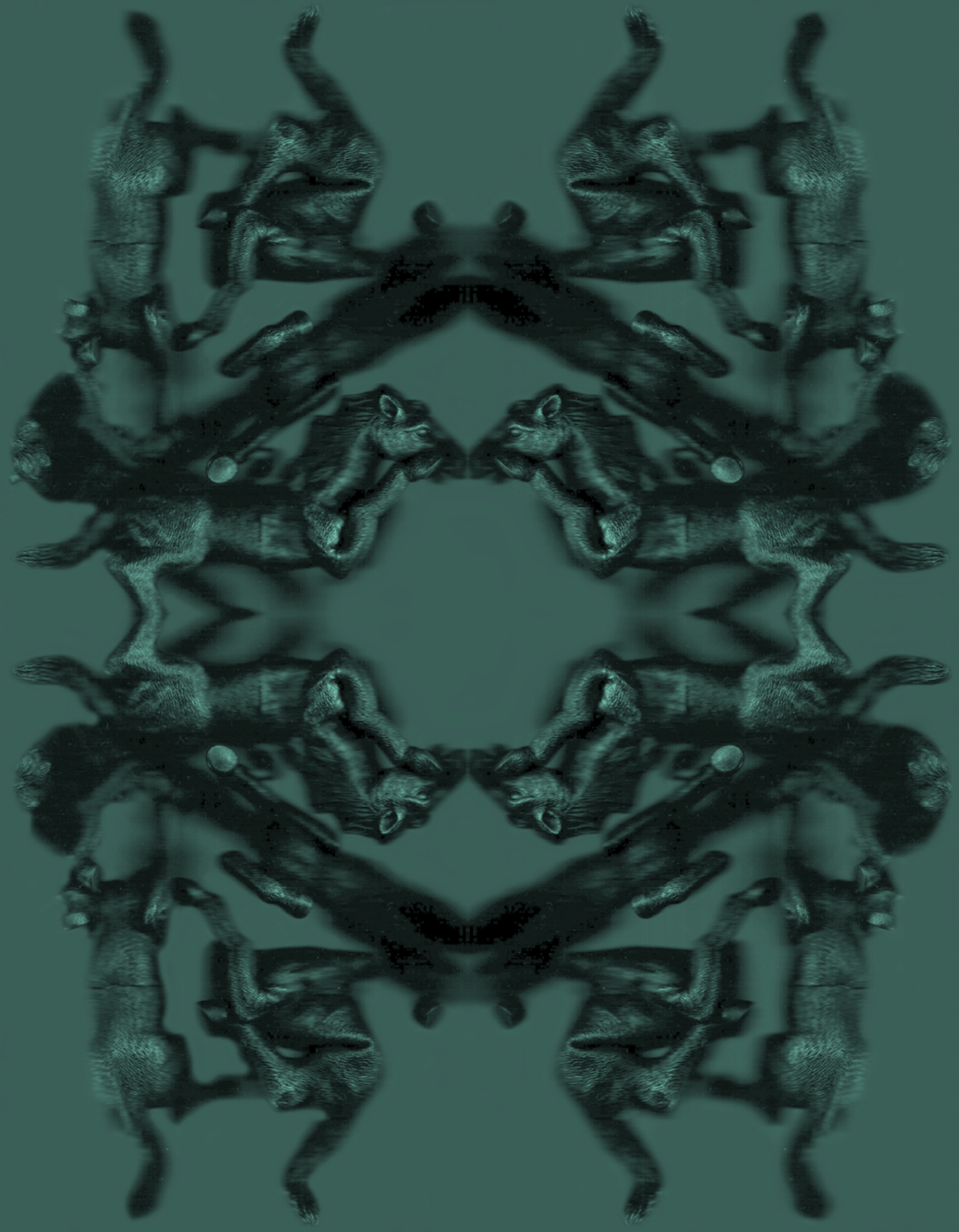


Letra, huella, trazo: reflexión sobre la historia, la memoria y el olvido desde el sentipensar

\begin{abstract}
Resumen
El ejercicio vital de rememoración a manera de viaje al pasado en el que permanentemente nos vemos inmersos en condición de seres pensantes, sintientes y actuantes y la respectiva influencia en cada una de las dimensiones de nuestro ser presente, ha despertado mi interés por reflexionar sobre la memoria asumida como un legado que se obtiene de manera progresiva desde y por medio de lo vivido. Este artículo presenta de manera poético reflexiva algunos principios básicos producto de esta aventura desplegada en el espacio y el tiempo para comprender la memoria y la corporeidad.
\end{abstract}

\title{
Palabras Clave
}

Poética reflexiva; percepción; prácticas sensibles; colonialidad del ser; memoria; olvido

Letter, Trace, Stroke: A Reflection on History, Memory and Oblivion Through Sentipensar

\begin{abstract}
The vital exercise of remembrance as a trip to the past in which we permanently see ourselves immersed, given our condition as thinking, feeling and acting beings, and the respective influence of each in every dimension of our present being, has awakened my interest in reflecting on memory as a legacy that is obtained progressively through and from lived experience. This article presents, in a reflective-poetic manner, some basic principles that stem from this adventure deployed in space and time - to understand memory and corporeality.
\end{abstract}

\section{Keywords}

Reflective poetics; perception; sensory practices; coloniality of being; memory; oblivion

Lettre, trace, trait : une réflexion sur l'histoire, la mémoire et l'oubli dès le sentipensar

\section{Résumé}

L'exercice vital du souvenir en tant que voyage dans le passé dans lequel nous nous voyons nousmêmes immergés en permanence - étant donné notre condition d'êtres qui pensent, ressent et agissent - et l'influence de cette condition dans chaque dimension de notre être présent, ont éveillé mon intérêt pour réfléchir sur la mémoire comme un héritage qui s'obtient progressivement à travers et à partir d'expériences vécues. Cet article présente, de manière réflexive et poétique, quelques principes de base issus de cette aventure, déployée dans l'espace et dans le temps pour comprendre la mémoire et la corporalité.

\section{Mots clés}

Poétique réfléchissante ; perception ; pratiques sensoriales ; colonialité de l'être ; mémoire ; oubli

Letra, pegada, traço: Uma reflexão sobre a história, a memória e o esquecimento através do sentipensar

\section{Resumo}

O exercício vital da recordação como uma viagem ao passado em que nos vemos permanentemente imersos, dada a nossa condição de seres pensantes, sencientes e atuantes, e sua respectiva influência em todas as dimensões do nosso ser atual, despertou meu interesse em refletir na memória como um legado que é obtido progressivamente a partir da experiência vivida. Este artigo apresenta, de forma poético-reflexiva, alguns princípios básicos que derivam dessa aventura - implantada no espaço e no tempo - para compreender a memória e a corporeidade. 
Palavras-chave

Poética reflexiva; percepção; práticas sensoriais; colonialidade do ser; memória; esquecimento

Kilka, huella, trazo, allilla iuiarii antiuamanda, sug iuiai i kangarii sintiluiaimanda

\section{Maillallachiska}

Kai iachaikui iuaringapa rikugsina kainama chipi kaurinchimi iuiaiug runa sintidurkuna ruradurkuna maipe naipe imasa Nukanchipa kaugsaipe nukata rigchachiura sug iuiarii allilla sakiskata i iukangapa,mailla imasa kaugsaskakai kilkaskapi kauachiku poético allilla iuiai mailla principiokuna uairapi i tiempope iachaikungapa iuiai i Corporeidad.

\section{Rimangapa Ministidukuna}

Poética allilla iuia; percepción; ruraikuna sensibles; colonialidad; nokapa; iuiai; kungarii 
El marino vuelve a encontrar, contento, su apacible río, tras haber viajado por lejanas islas y haber hecho su comercio. También yo regresaría feliz a mi tierra si hubiera cosechado tantos bienes como estos males que traigo.

Hölderlin

El trayecto discursivo de esta reflexión pondrá en evidencia la manera en que su núcleo puede bifurcarse en caminos diferentes bajo un mismo patrón conceptual, la primera sección parte del planteamiento de la memoria desde el ámbito filosófico y autoexperiencial de la tierra natal a partir de la cita de referentes teóricos importantes como son: Paul Ricoeur, Anna Pagès, Maurice Merleau Ponty, entre otros; y luego, rebosar en una segunda sección que se libera a un lenguaje poético de evocación de nuestra casa, asociada como lugar idílico cúmulo de infinitos sentidos, para finalmente cerrar a manera de conclusión con una invitación directa al lector sobre su propio ejercicio reflexivo, de tal manera y teniendo en cuenta esta aclaración, pasemos a la primera sección.

\section{Augurio para evocar}

Auguro casa como el espacio donde habitan los mejores recuerdos; auguro casa como el sentido que ata la razón a la espiritualidad del habitar y al corazón, auguro tierra natal como la madre y el desplazamiento como el padre de la nostalgia, auguro casa como el suplemento vital para el retorno.

Como máquina de tiempo, mi gusto por piezas nostálgicas de la música clásica ha ido despertando curiosidad por temas que tienen que ver con lo pasado porque precisamente, eso es lo que me evocan; cuando a mis 18 años, en la carátula de uno de mis primeros discos compactos leí la genealogía de la Sinfonía del Nuevo Mundo del compositor Antonin Dvořák, compuesta en 1893, a raíz de la nostalgia que le embargó en New York su Nelahozeves natal, pude componer una de las ideas globales más importantes en torno al problema de la memoria, en primera instancia desde la vivencia visceral de desplazamiento y nostalgia de este compositor plasmada por medio de la música, y en segunda instancia desde la adopción comparativa de dicha obra maestra con mi propia infancia nómada, la cual se desarrolló deambulando de la mano de mis padres y hermanos sobre las precarias sendas terrestres que comunican los departamentos de Nariño, el bajo Putumayo y la selva de la Bota Caucana, en busca de dinero y mejores condiciones de vida. Dos condiciones a simple vista lejanas una de la otra que pueden encontrarse en una relación preponderante en cuanto a ser cada una, un referente vivencial y motivo de creación, asociadas al desplazamiento, la nostalgia y el deseo de retorno a la tierra natal en todas sus posibles dimensiones.

Cabe anotar que en el ámbito familiar, el desarrollo de estos desplazamientos han marcado una de las más relevantes experiencias en nuestra vida colectiva de familia y que se han ido grabando cada vez más profundo con el paso de los años, a través de este ejercicio reflexivo, se matizan con aspectos e ideas más densas como son, por ejemplo, la importancia que tiene el sentido de lo dejado en el presente, o el pasado como lugar y tiempo transitable de ires y venires a través de la rememoración que precisamente alrededor de la dimensión que nos habita y que habitamos nos hace vivir el reencuentro con aquellos ausentes, imágenes y/o sensaciones de lo vivido el -Eikon platónico- o la idea de aquella imagen casi visual del pasado presente (Ricoeur, 2007).

La relación de la perspectiva biográfica de Dvořák con la de mi propia experiencia de desplazado, por tanto me ha permitido comprender la necesidad e importancia que tiene la reflexión sobre el cómo y el porqué del desplazamiento tanto físico como espiritual de retorno a la tierra natal, a manera de una cura posible para la nostalgia que embarga lo dejado, o, en lo que Ana Pagés en su libro Al filo del pasado define como "un desliz en el tiempo", un desliz que permite estar acá y allá, ahora, antes y después en una especie de viaje plasmado si se quiere en los horizontes de la corporeidad, presente en continuos viajes de ida y vuelta presente-pasado.

Desde las perspectivas de presencia-ausencia afloradas entre el presente-pasado, como facultad del ser pensante, sintiente y actuante que está aquí y allá, ahora, antes y después surge la perspectiva de la corporeidad, como un despliegue del cuerpo sensible pensante; si bien es cierto, el presente del sujeto desplazado se presta para continuos desplazamientos a través de la memoria y sentir en el presente lo pasado, en un rehabitar lo pasado y la ausencia evocada por la huella, que son por así decirlo el presente, literalmente como regalo o propiedad que otorga lo pasado, conocimiento, saber, experiencia, vida. 


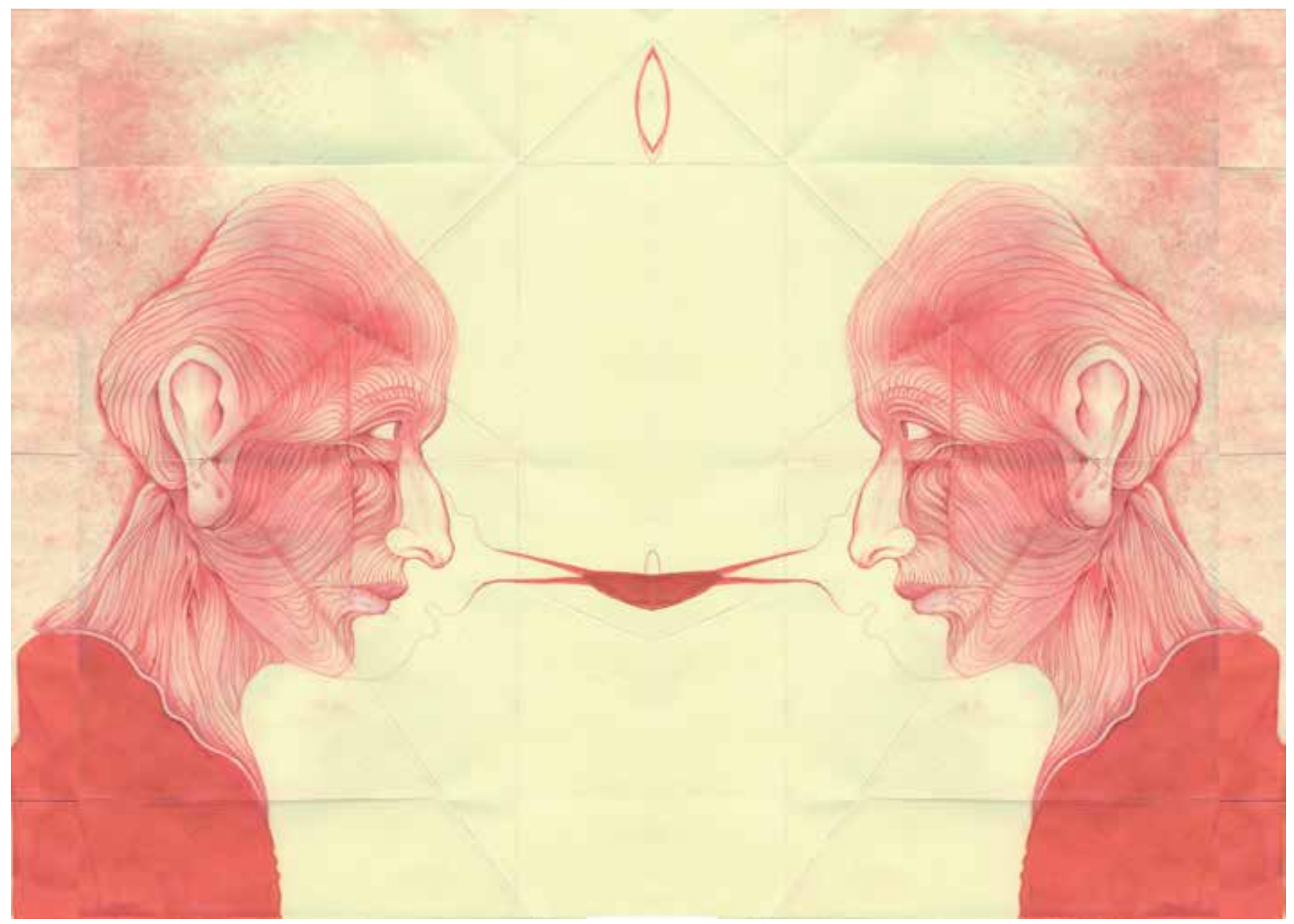

Imagen 1. Segundo encuentro. Introspección. (Jesús Holmes Muñoz. 2019). Dibujo a lápiz e intervención digital.

De esta manera, el recuerdo de la tierra natal y de la casa que me acogió los primeros años de vida pueden ser presentados como espacios y plataformas vivas, palpitantes, colectivas e ilustrativas de un ejercicio de viaje al pasado ya que, por otra parte, al entrañarme en aquella vieja casa de paredes y pisos de tierra, asumida como el lugar donde alrededor de la pobreza junto a mis padres y mis cinco hermanos viví los momentos más emotivos y profundos de mi vida, los cuales hasta el día de hoy vibran, puedo ilustrar el modo en que cada una de sus dimensiones (visuales, olfativas, táctiles y o sensibles) se conectan a cada uno de los sentidos de mi cuerpo y se aúnan en el sentido del pasado en el de la memoria.

Todo esto puede encontrar relación con aquella indagación que hace Bachelard en La poética del espacio, sobre la idea de leer una casa, e introspectar sobre cada una de sus funciones vitales alrededor de nuestro ser sensible, también en la manera como este espacio modifica y estimula nuestra precepción en un extraño compendio de objetos y espacialidades que se fusionan en nuestra propio ser.

Con respecto al tema, dice Bachelard: " "leer una casa", "leer una habitación", tienen sentido, puesto que habitación y casa son diagramas de psicología que guían a los escritores y a los poetas en el análisis de la intimidad" (Bachelard, 1965, p. 70).

Sin embargo, en este preciso espacio reflexivo, diré que más que ser solo guías para poetas y escritores, la evocación del espacio casa y la tierra natal asumida también como casa, se convierte en un campo vital, mucho más compenetrado con la intimidad, al cual todo ser humano de alguna forma se encuentra conectado, puesto que se trata directamente con aquellas espacialidades y temporalidades donde dio sus primeros pasos y afloró sus primeros años de vida, por esa razón mi campo de indagación más que referir una casa asumida como espacio, refiere el de una casa-recuerdo y viviente, el presente del pasado o el pasado presente de 
la casa que habitamos físicamente y que tras nuestro abandono a partir del desplazamiento se convierte en lugar de evocaciones múltiples.

Al recordar el olor y sabor del café de la mañana, hervido con leña de bosque y endulzado con jugo de caña en mi niñez, mi nariz, lengua y corazón se repliegan hacia una nueva dimensión alimentada por el recuerdo y la imaginación, ahora bien, valga la pena resaltar que el término imaginación dentro del ámbito de la memoria es una de las piezas claves que posibilitan la composición y funcionamiento de esa "máquina del tiempo", sobre todo a la hora de ilustrar por cualquier medio el pasado, pero, valga la pena también, tener en cuenta la diferencia planteada por Paul Ricoeur entre memoria e imaginación, en su primer capítulo titulado: De la memoria y la reminiscencia, del libro La memoria, la historia, el olvido, dice:

Debe procederse, lo más que sea posible a la separación de la imaginación y la memoria. La idea guía es la diferencia, que podemos llamar eidética, entre dos objetivos, dos intencionalidades: uno, el de la imaginación, dirigida hacia lo fantástico, la ficción, lo irreal, lo posible, lo utópico. Otro, el de la memoria, hacia la realidad anterior, ya que la anterioridad constituye la manera temporal por excelencia de la "cosa recordada", de lo "recordado" en cuanto tal (Ricoeur, 2003).

De manera que, siguiendo con el ejercicio de reconstrucción de aquella casa perdida tras ese extraño paso en el espacio y el tiempo, e impresa en mi ser, bajo los patrones del pensamiento de Ricoeur sobre la idea de la memoria, el recuerdo y la imaginación plasmadas en dos ideas claves que cita de manera puntual desde Platón y Sócrates, la del Eikón y la de la metáfora del trozo de cera; la primera que hace referencia a la teoría platónica del eikón en la que subraya principalmente la idea de una cosa ausente, quedando implícita la referencia al pasado (p. 22), la representación presente de una cosa ausente (p. 24), y la segunda que se refiere a la idea de un trozo de cera sobre el cual por medio de la memoria e imaginación podemos imprimir o tallar nuestra imagen del pasado:

Un bloque maleable de cera: mayor en unas personas, menor en otras; de una cera más pura para unos y más adulterada para otros; unas veces, más dura, y otras, más blanda y en algunos en término medio (...) pues bien, digamos que es un don de memoria, la madre de las musas aquello de que queremos acordarnos de entre lo que vimos, oímos o pensamos, lo imprimimos en este bloque como si imprimiéramos el cuño de un anillo. Y lo que se imprimió lo recordamos y lo sabemos en tanto su imagen (eidólon) permanezca ahí (Ricoeur, 2003).

Podré desplegar una nueva dimensión hacia el ejercicio de reconstrucción de mi casa natal como el motivo principal de composición de esta reflexión, además sustentar el ejercicio descriptivo por medio del juego de palabras como forma de impresión sobre ese bloque de cera, e inaugurar con ello la imagen cuasi visual de un lugar perdido, rememorado, en miras de fijar una propuesta plástica-literaria de composición de mundos presentes ausentes.

Pero, tras el retorno, valga la pena también tener en cuenta la idea de ruina, en el buen sentido de la palabra, con relación al recuerdo y al bajo presupuesto de fidelidad que brinda dicha imagen tomada desde la memoria y la vivencia - aquellos detalles de la casa que han quedado escritos en la memoria-. Si bien es cierto, en su libro Al filo del pasado, Anna Pagés demuestra que tras el regreso a la tierra natal nada de lo que dejamos pervive, pues todo lo ha cambiado el tiempo que carcome. Aquel camino de tréboles en flor evocado por Los Olimareños en su versión de la canción Nuestro camino, ${ }^{1}$ en cuya letra definen la manera en que poco a poco, un lugar de experiencias amorosas y viscerales de una pareja de jóvenes amantes de colegio va siendo carcomida por entre malezas del bosque, llevándose a su paso todos aquellos momentos de un amor trivial.

... yo iba solito hasta la sombra de los pinos, con el camino a conversar.

Pero una tarde no lo hallé, lo habían tapado, igual que ayer, los macachines y los tréboles de olor. su tumba en flor, iqué triste ver!

En la experiencia de lo dejado, tras sus ruinas viene el olvido, pero es el retorno el acto que posibilita la recapitulación de lo vivido y aún más a fondo el que permite enmarcar la importancia de la memoria como esa dimensión y facultad maravillosamente restauradora, reconstructora, evocadora y sensible de lo dejado, como ese nuevo sentido enraizado en el sentimiento de lo pasado; rememorar es revalidar y hacer palpables los reflejos del pasado en el presente.

1 Canción del álbum musical, Donde arde el fuego nuestro, de Los Olimareños(2006). 
Así, con respecto a aquel lugar llamado mi tierra natal y mi casa materna paterna, sucede algo similar con el evocado por Los Olimareños en su canción; físicamente ya nada queda porque nuestra vieja casa fue vendida hace casi 30 años a don Fidel Urbano, un paisano que la cambió completamente: reemplazó sus colores y texturas con nuevas arquitecturas y materiales, todos aquellos lugares, rincones, huellas, escondrijos, y recuerdos se evaporaron hacia nuestra memorias, ${ }^{2}$ pero para bien de su arquitectura, precisamente, allí fue donde cobró más fuerza y valor, sus tapias se cimentaron en un nuevo predio donde los materiales para su restauración son infinitos, donde no hay linderos ni leyes de ingeniería y arquitectura y donde se pueden erguir nuevamente como magníficos lugares trastocados en y por cada una de las partes del cuerpo.

Entonces, redondeando la idea de memoria a partir de las anteriores consideraciones, en el sentido experiencial y literario es posible asumirla como una verdadera herramienta, clave para la reconstrucción cuasi visual de los aspectos con que se identifican los lugares, situaciones, sentidos, afectividades, prosaicas y poéticas de los pasados espaciales y temporales que tras el desplazamiento, a medida que se fueron opacando y carcomiendo, fueron adquiriendo más valor por ser legados de nuestro pasado. Un legado que también acrecienta el deseo de retorno, en mi caso particular de reconstrucción de aquella casa, en miras de hacerla palpable, de fotografiarla y mostrarla como un presente, como la prueba clara de que la rememoración confluye en la reconstrucción de un espacio-tiempo perdidos.

Es preciso decir que nuestro paso por el mundo imprime huella con relación a nuestro recuerdo, también a ser recordado, a formar parte de otros mundos, de otras memoria, de otros seres que recuerdan, en el preciso sentido donde la memoria y las memorias comienzan a compenetrarse en un todo recíproco e integral que bien podríamos relacionar con lo que llamamos corporeidad. (Castillo, 2013)

\footnotetext{
2 Memoria colectiva, compuesta por mis padres Ana Rosa Gómez y Ricardo Fenelón Muñoz y mis hermanos(as): Ricardo, Fabiola, Luz Dary, Jorge y Paola.
}

\section{Evocación de la tierra}

Habitando una penumbra todos los días rota por tímidos rayos de mediodía que entraban por los agujeros del techo y golpeaban las ennegrecidas tapias, tuve la suerte de nacer y crecer junto a cinco hermanos en una casa de tejas de barro y paredes polvorientas plantadas sobre tierras desnudas donde nuestras caras siempre permanecieron tras mascarillas de polvo y moco.

(Familia) junto a mi madre y cinco hermanos he ido siguiendo en procesión el paso de una ordinaria y tosca caja de madera en forma de ataúd que mi padre construyó para cargar las pesadas prensas y martillos de metal de su herrería por senderos peligrosísimos y abismales, entre otros, por el llamado "trampolín de la muerte", en la vía que comprende el alto y bajo Putumayo, destino donde pudimos degustar el sabor del mico, el tigrillo, el venado y la panguana en platos que compusieron verdaderos manjares juglares.

(Agua) hemos jugado con la muerte por encima de suaves bancos de arena y arcilla en las playas del caudaloso río Caquetá, encontrando anclados en troncos y ramas, espantosos personajes descompuestos por su viaje funerario río abajo entre piedras filosas, aguas torrentosas y fauces de peces carniceros que les desfiguraron.

(Aire y fuego) la ventiladora, una máquina crujiente y ruidosa compuesta con bandas de goma, ruedas y poleas cuyo objetivo es el de empujar bocanadas continuas de aire y mantener carbones al rojo vivo, como implementos de clases prácticas impartidas por nuestro padre sobre el arte de la fundición, la soldadura, la forja y la fragua del acero en juego de metal derretido y composición de extraños artefactos personalizados con la huella de nuestras necesidades vitales.

(Sonoridades) tuve la suerte de crecer entre sonidos y notas musicales marcadas por la herencia de mi abuelo materno, gran guitarrista, que con su legado popular aún hoy nos pone a suspirar, y por la huella de las manos de mi abuelo paterno, quien fue un alfarero que supo grabar en cada uno de sus objetos su vida.

(Tierra) viví entre campesinos y leñadores, entre herreros y carboneros, entre alfareros que forjaron con sus manos y su resuello nuestra vida, aprendiendo a manufacturar nuevas formas de saciar necesidades primordiales desde y con la tierra. 


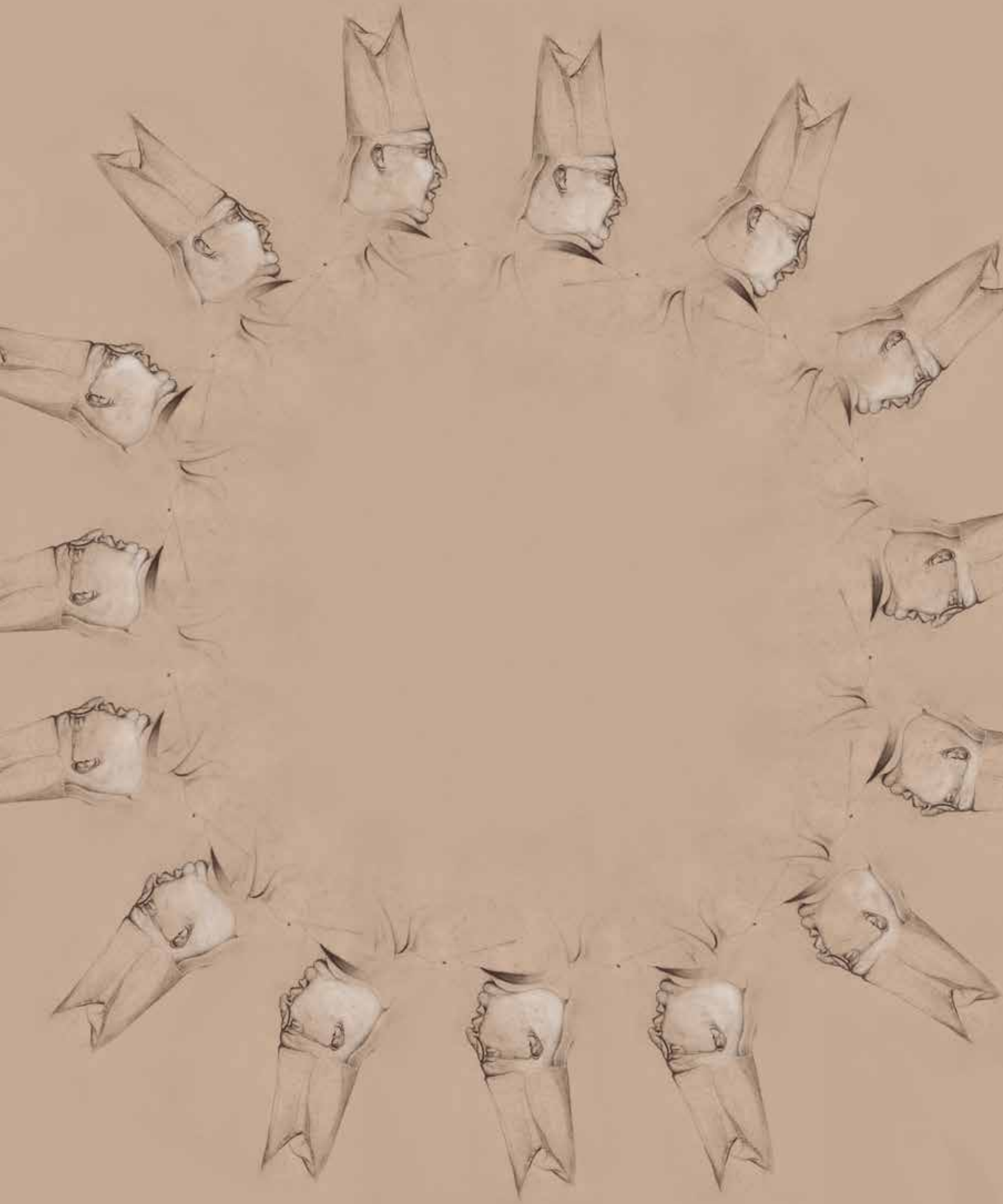

Imagen 3. Cuarto encuentro. El señor Obispo. (Jesús Holmes Muñoz, 2019). Dibujo a lápiz e intervención digital. 
Entre casas levantadas con ladrillos y tejas de barro quemadas con leña olorosa y fresca en aquellos hornos, en los cuales, también quemaron y fundieron parte de su vida. Entre parcelas que producen hierbas y plantas comestibles provenientes de una tierra libre de compuestos venenosos, brindándonos sabores, olores y texturas ancestrales en nuestras tasas de sopa.

He tenido la fortuna de tocar la ocarina de barro y materializar a mis abuelos en un soplo convertido en canción.

Hemos llegado al mundo guiados por Doña Angelita Jojóa, vieja partera que ya descansa sobre el regazo de su tumba. También aprendimos de los viajes épicos de don Jesús Antonio Muñoz Alvear, sabio agricultor que se ha ido quedando ciego en su chacra y que en sus años mozos fue viajero, mujeriego y mordaz acompañado siempre por su afilado machete.

Hemos sido curados bajo el poder y la sabiduría de don Abel Gómez, un médico que habla con las plantas y puede ver lo invisible a través de un vaso con agua, hemos comido aquellas moras que crecen en las tapias en ruina de nuestro viejo cementerio y también, hemos bebido el agua de cada una de las pocetas que fluyen de los húmedos barrancos musgosos de los senderos grabados en los mapas de nuestra mente. Hemos jugado con tierra y probado a bocanadas las paredes de adobe de nuestra casa, sabores y olores que aunque lejanos mantienen mi lengua aún pegada a ellas.

(Carnaval) Somos músicos de ocarinas y pinquillos de barro, hemos venido tocando canciones a la tierra y bailando descalzos danzas de la vida, disfrazados de oso y matachines con musgos y hojas de achira en carnaval, enfuertando nuestra chicha de naranja en botellas de vidrio que se depositan en el vientre de la tierra, embriagándonos con su frescura ancestral.

Vamos viajando por senderos perdidos entre la gaspada senda del frailejón buscando la cumbre de viejos volcanes y lagunas emparamadas, a la caza del pato silvestre, el erizo, la pava y la torcaza.

Mis padres y mis ancestros han trabajado la tierra entregando y fundiendo su vida a ella. Agricultura, cerámica y alfarería componen su carne, su alma, la fuente de su vida y la nuestra. Económica, social, cultural y políticamente somos tierra, encarnados en tareas unificadoras, relacionales, tejedoras de formas de hacer, compartir y prevalecer las memorias a través de una serie de trabajos transmitidos y grabados en la piel del tiempo. ${ }^{3}$

\section{Consideraciones intermedias}

A fuerza de las anteriores reflexiones y la Evocación a la tierra, es posible ir aterrizando ideas concretas sobre la memoria presente en el ser (verbo) sensible y pensante de un ojo y un espíritu que se conjugan, por así decirlo, en un mismo sentido.

Por esta razón, sin desligar el discurso del tema central que es la memoria y sin deshilar la descripción anterior, valga la pena hilvanar el siguiente apartado para el tejido de dos nuevos conceptos que giran en torno a nuestro tema central, uno que corresponde a la idea de un cuerpo que se repliega de la carne y el hueso para habitar nuevas dimensiones a través de aquellos viajes por el tiempo, y dos una fenomenología o estudios de la percepción, que en el sentido de la memoria lleva a un cuerpo suspendido en la inespacialidad y la atemporalidad de su propia percepción, en cercana armonía con lo que Merleau Ponty proclama en su libro El ojo y el espíritu, eh ahí la importancia de revisar este texto, pues si bien es cierto en algunas de sus líneas se fractura de manera efectiva la idea convencional de cuerpo-espíritu, para fijar un concepto que desde mi punto de vista tiene relación con lo que podría denominarse corpoespiritu, en cuyo alcance se sobrepasa las leyes aparentemente racionales del dualismo y se fijan más bien en un plano basado en un cuerpo relacional, sintiente, pensante y actuante que se despliega a cada una de las partículas que componen su mundo, precisamente allí donde la presencia del otro y de lo otro se corresponden de manera recíproca en el yo estoy y soy; puesto que yo formo parte y estoy en el mundo del otro y el otro forma parte y es del mío desde y a través de la experiencia que se guarda como memoria.

De esta manera, y retomando el aspecto concerniente a los viajes de retorno a la tierra natal en todas las dimensiones corporales descritas anteriormente, se puede asumir el sentido de la memoria como un poder de alcance que se fija en el pasado para fortalecer el presente sensible, lo cual también puede verse reflejado en el actuar, y en el pensar.

3 Descripción de mi vida, contenida en el trabajo de grado de maestría. Escrita en el año 2013 y actualizada en el 2018. 


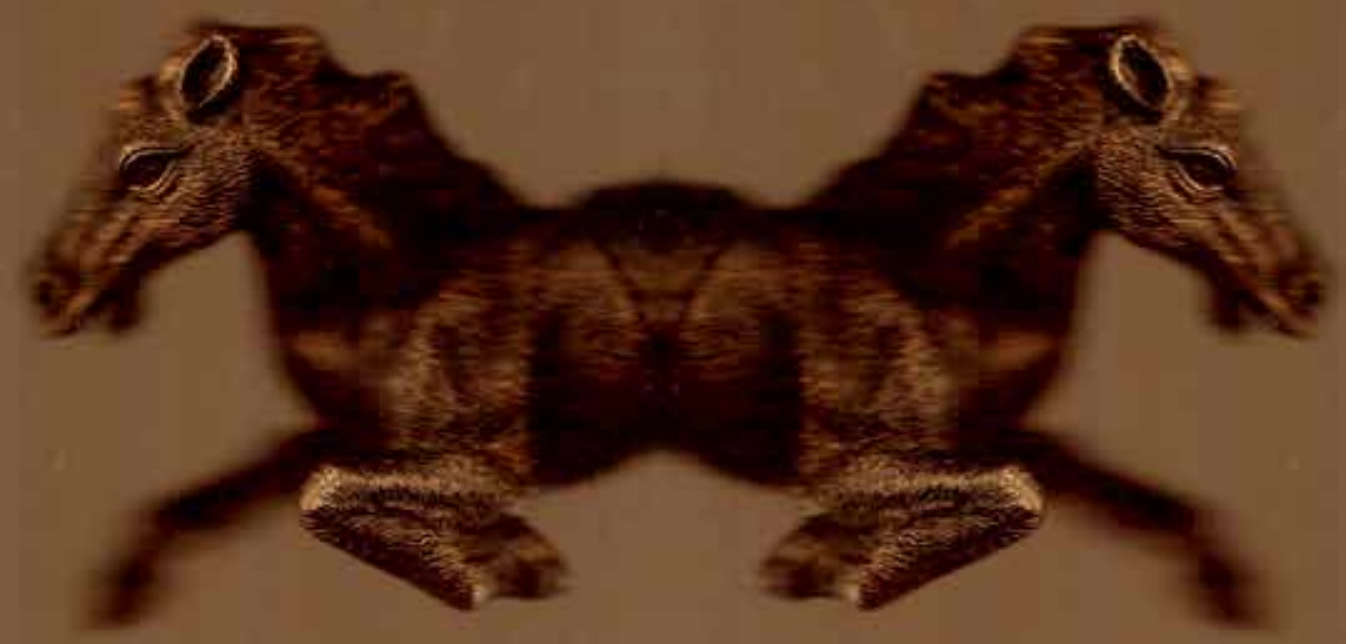


Centrándonos en la visión del ojo y el espíritu con el fin de fortalecer el concepto de desplazamiento y memoria, fijemos la reflexión en su idea de la fenomenología de la percepción como preocupación central, la cual, se resuelve de manera eficiente desde la fusión de esas dos dimensiones en el título de su libro. Un ojo y un espíritu llevados a plano de mi preocupación podrían corresponderse de manera relativa a una formula especifica basada en la experiencia de desplazamiento físico de un ser corporal, la memoria de dicha experiencia guardada por el ser desplazado y el retorno como un nuevo desplazamiento basado en nuevas cualidades de ser (verbo) de hacer (memoria) y de sentir (recuerdo) en calidad de lo tangible e intangible, la percepción de la memoria precisamente, el sentir del pasado presente por medio y a través del cuerpo.

Sin embargo, y valga la pena referenciarlo, el salto de lo poético promulgado en la primera parte y lo reflexivo en esta segunda, precisamente lleva a entonar la lógica de los estudios artísticos como verdaderos campos de experimentación sensible y pensante, donde las prosaicas y las poéticas encuentran su lugar, su cruce de caminos como diría Sandro Romero Rey (2017). De esta manera, partiendo de la idea del pensamiento hermenéutico de Ricoeur, sobre la memoria y el olvido, pasando por la lectura que hace Anna Pages sobre el desplazamiento y el retorno a la tierra natal a partir de textos de Heidegger, de mi experiencia vital de desplazado y de ser plantado en el presente pasado y la fenomenología de la percepción instaurada por Merleau Ponty en el ojo y el espíritu, se puede concretar de manera poético reflexiva una importante tarea, muy necesaria por cierto para cada uno de los estimados lectores, establecer su propia definición de memoria a partir de los conceptos descritos a lo largo de este texto y de los precedentes de su propia experiencia, de su propia historia sensible del pasado presente. (Romero Rey, 2017)

\section{Referencias}

Bachelard, G. (1965). La poética del espacio. México D.F.: Fondo de Cultura Económica.

Castillo-Ballen, S. (2018). Editorial. Revista Corpografías. Estudios críticos de y desde los cuerpos, 3(3), 7-9. https://doi.org/10.14483/25909398.13139

Castillo-Ballen, S ( 2011). El cuerpo sintiente en las artes del cuerpo. Biblioteca Artes plásticas Universidad de las artes ISA Cuba. 2012

Courtoisie, R. (2008). Poesía y caracol. Fundación BBVA.

Romero Rey, S. (2017). Cruce de caminos. Bogotá: Universidad Distrital Francisco José de Caldas.

Muñoz, J, H. (2016). “Mi gallina y otro" Fábula macabra en el campo de los estudios artísticos. Estudios Artísticos: revista de investigación creadora, 2 (2) pp. 107-118. DOI: 10.14483/udistrital.jour. ear.2017.1.a07

Manns, P. (2003). Memorial de Bonampak - Poesia. Valencia: Brosquil Ediciones.

Merleau-Ponty, M. (1964). (trad.2013). El ojo y el espíritu. Madrid: Minima Trotta.

Pagès, A. (2006). Al Filo del pasado. Filosofía hermeneutica y y transmisión cultural. Barcelona: Herder.

Ricoeur, P. (2003). La memoria, la historia, el olvido. Madrid: Editorial Trotta.

Los Olimareños.(2006). Donde arde el fuego nuestro. [CD, Álbum, Reissue]. Uruguay: Sello Bizarro Records. 